\title{
Synthesis of Cardanol-Based Novolac Resin from Cashew Nut Shell Liquid
}

\author{
Putri Rahmawati ${ }^{1}$, Ari Handono Ramelan ${ }^{2}$, Soerya Dewi Marliyana ${ }^{1}$, Neng Sri \\ Suharty ${ }^{1}$ and Sayekti Wahyuningsih ${ }^{1 *}$ \\ ${ }^{1}$ Department of Chemistry, Faculty of Mathematic and Natural Science, Sebelas \\ Maret University, Surakarta, Indonesia \\ ${ }^{2}$ Department of Physics, Faculty of Mathematic and Natural Science, Sebelas \\ Maret University, Surakarta, Indonesia \\ "Corresponding author: sayekti@mipa.uns.ac.id
}

Published online: 30 April 2019

To cite this article: Putri Rahmawati, Ari Handono Ramelan, Soerya Dewi Marliyana, Neng Sri Suharty and Sayekti Wahyuningsih (2019). Synthesis of cardanol-based novolac resin from cashew nut shell liquid. Journal of Engineering Science, 15, 23-33, https://doi. org/10.21315/jes2019.15.3.

To link to this article: https://doi.org/10.21315/jes2019.15.3

\begin{abstract}
Phenolic resin is a kind of polymer product obtained through several types of polymerisation process of natural or synthetic materials. One of natural compounds that can be applied for polymer manufacture is cardanol. By means of this research, cardanol has been successfully isolated from cashew nut shell liquid (CNSL) through liquid-liquid extraction methods while cardanol-based novolac resin was synthesised from obtained isolate and formaldehyde was synthesised by addition of citric acid as catalyst. Both isolated cardanol and cardanol-formaldehyde (CF)-based novolac resin were being confirmed by Fourier transform infrared (FTIR) and nuclear magnetic resonance (1H NMR). thermogravimetry-differential thermogravimetry (TG-DTA) analyser were undertaken to analyse thermal stability of the resin. Based on FTIR spectras and 1 H NMR spectroscopy, $C F$-based novolac resin was successfully synthesised through polycondensation reaction. Thermal stability of isolated CF resin showed high degradation temperature of $282^{\circ} \mathrm{C}$.
\end{abstract}

Keywords: cardanol, CNSL, novolac, resin

\section{INTRODUCTION}

Resin is one of important material that is used in several industrial fields. Several types of synthetic resin that is commonly used in industrial sectors are epoxide, polyure-thane, alkide, phenolic and silicate. But, considering health hazard, handling issues and toxicity, the use of those resins is attempted to be 
substituted by natural based resin. Cashew nut shell liquid (CNSL) is one of the most applicable renewable resources for producing resin because its low cost, safe and environmental friendly. ${ }^{1,2}$

CNSL is largely spread over tropical countries, including Indonesia. There are two types of CNSL based on its processing i.e. natural and technical CNSL. ${ }^{3}$ Natural CNSL is extracted using chemical solvent and contains anacardic acid (60\%-65\%), cardol (15\%-20\%), cardanol (10\%) and traces of methyl cardol. On the other hand, technical CNSL is obtained by roasting process of cashew nut shell kernel and produce mainly cardanol $(60 \%-65 \%)$, cardol $(15 \%-20 \%)$, polymeric material (10\%) and traces of methyl cardol. ${ }^{4,5}$ Cardanol, the major compound of technical CNSL is very difficult to synthesise through conventional chemical process due to long aliphatic said chain found in meta position. As the presence of reactive groups such as hydroxyl group, aromatic ring and double bond on side chain leads cardanol to be chemically modified. ${ }^{6}$ For refining cardanol, there are various methods that had been used like column chromatography, distillation with reduced pressure and liquid-liquid extraction.

Cardanol is already used for manufacture of phenolic resins. Cardanolbased phenolic resins are regularly synthesised through polycondensation reaction with electro-philiccompounds, such as formaldehyde, furfuraldehyde or benzaldehyde. ${ }^{7,8}$ Cardanol based phenolic resin was also prepared by the reaction of formaldehyde (F) with cardanol (C) and depending of the F:C molar ratio and the type of catalyst the reaction can lead to either a resole or a novolac type of phenolic resin. ${ }^{9}, 10$ This work was focused on the preparation of cardanol-based novolac resin by reaction of cardanol dan excess formal-dehyle with the presence of citric acid as catalyst. Polymerisation of cardanol by formaldehyde will form cardanol-formaldehyde (CF) as natural resin.

\section{METHODOLOGY}

\subsection{Materials}

Technical CNSL was obtained from PT Guna Mete Mojosongo (Surakarta, Central Java, Indonesia). Ammonium solution, methanol, hexane, hydrochloric acid $(\mathrm{HCl})$ and sodium sulfate anhydrous from Merck. Several analytical reagent for synthesis resin such as aqueous formaldehyde (37\%) and citric acid were also obtained from Merck whereas chloroform was used for purification. 


\subsection{Cardanol Preparation from CNSL}

Isolation of cardanol from CNSL was conducted by liquid-liquid extraction method. Technical CNSL (100 g) was dissolved in methanol (320 mL) and ammonium hydroxide $(25 \%, 200 \mathrm{~mL})$ was added and stirred for $15 \mathrm{~min}$. This solution was then extracted with hexane $(2 \times 200 \mathrm{~mL})$. The organic layer was washed with $5 \% \mathrm{HCl}(100 \mathrm{~mL})$ followed by distilled water $(100 \mathrm{~mL})$. Activated charcoal $(10 \mathrm{~g})$ was added to the organic layer, stirred for $10 \mathrm{~min}$ and filtered through Celite $(15 \mathrm{~g})$. The filtrate was dried over anhydrous sodium sulfate and concentrated to get pure cardanol. ${ }^{11}$ The obtained cardanol was then characterised using Fourier transform infrared (FTIR) Prestige 21 Shimadzu and nuclear magnetic resonance (Agilent $1 \mathrm{H}$ NMR $400 \mathrm{MHz}, \mathrm{CDCl} 3,25^{\circ} \mathrm{C}$ ).

\subsection{Synthesis and Purification of CF-Based Novolac Resin}

CF-based novolac resin was synthesised by the condensation reaction of cardanol $(3 \mathrm{~g})$ and $37 \%$ formaldehyde with various molar ratio cardanol to formaldehyde 1:0.5; with the using $1 \mathrm{wt} \%$ citric acid based on weight of cardanol as catalyst. Cardanol was taken into a $100 \mathrm{~mL}$ three-necked round bottom flask fitted with a condenser, thermometer and mechanical stirrer. The temperature was raised until $120^{\circ} \mathrm{C}$ along with the addition of catalyst. After the temperature stable at $120^{\circ} \mathrm{C}$, formaldehyde was then added drop wise in batches for $30 \mathrm{~min}$. The mixture was vigorously stirred and kept at $120^{\circ} \mathrm{C}$ for $5 \mathrm{~h}$. The system was allowed to cool down after the reaction finished. The products were then purified in order to remove un-reacted cardanol by in comparison methods of column chromatography using hexane: chloroform. In comparison, a recent suggested methods ${ }^{12}$ was conducted by extracting raw product using methanol for three times until methanol layer was transparent reddish colour. Then, the remaining product was further extracted by ethanol:methanol (1:2). The final purified product was obtained after being vacuum dried. Obtained product was characterised using FTIR and NMR spectroscopy. Thermal stability of the resin was then analysed using thermogravimetric analyser (TGA) (Lisensis PT 1600, heat rate $10^{\circ} \mathrm{C} \mathrm{min}^{-1}$, temperature target $900^{\circ} \mathrm{C}$ ). 


\section{RESULTS AND DISCUSSIONS}

\subsection{Characterisation of CNSL and Cardanol Using FTIR}

Isolated cardanol still has similarity in physical properties with CNSL. Both of them have dark brown reddish colour, similar odour and well dissolved in n-hexane and chloroform. But cardanol seemed has higher $\mathrm{pH}(6.8)$ than CNSL (4.97). The higher $\mathrm{pH}$ of cardanol was due to decarboxylation process to remove carbonyl group of anacardic acid from CNSL to obtain higher purity of cardanol.

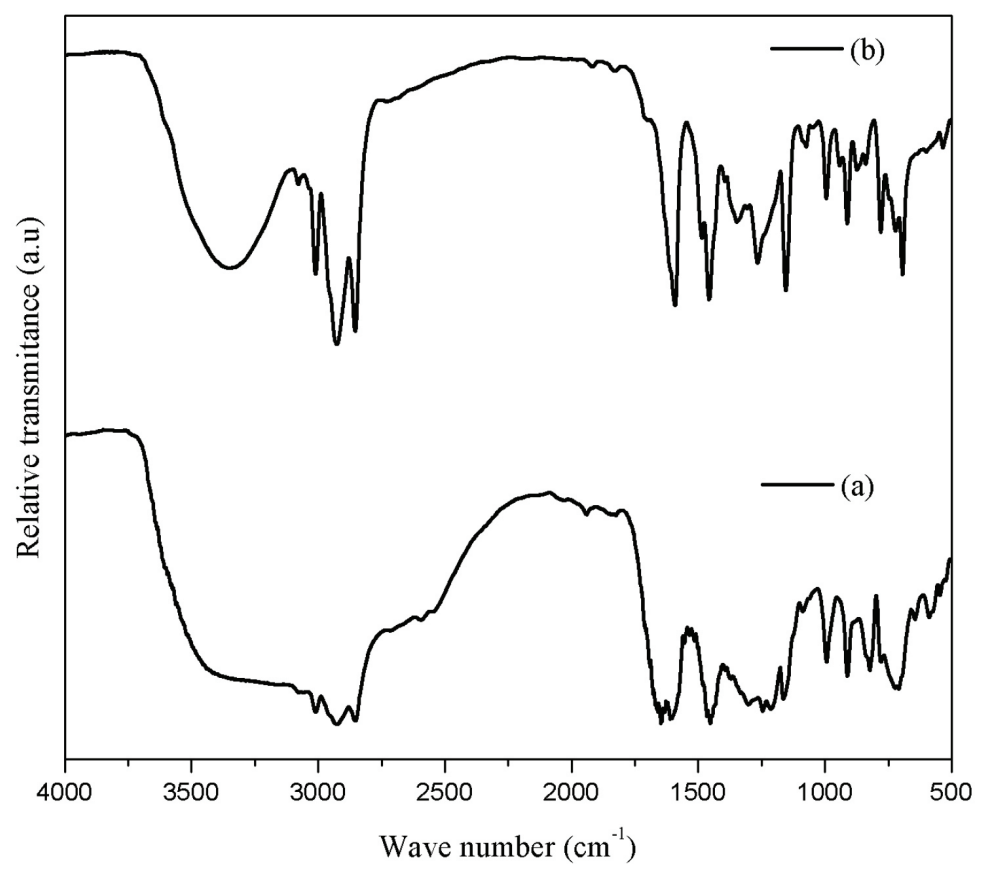

Figure 1: FTIR spectra of (a) CNSL and (b) isolated cardanol.

FTIR spectrums of CNSL and isolated cardanol were shown at Figure 1. Hydroxyl group of CNSL could be identified from emersion of peak at $3,172 \mathrm{~cm}^{-1}$ region. Widening hydroxyl peak of CNSL showed typical characteristic of a carboxylic acid, anacardic acid and was supported by the presence of very small peak at $2,595 \mathrm{~cm}^{-1}$ which was absorption of substituted carbonyl at aromatic group. The loss of peak at $2,595 \mathrm{~cm}^{-1}$ and the sharpening of hydroxyl peak on cardanol at $3,334 \mathrm{~cm}^{-1}$ could be assumed as the loss of $\mathrm{C}=\mathrm{O}$ group from anacardic acid. 


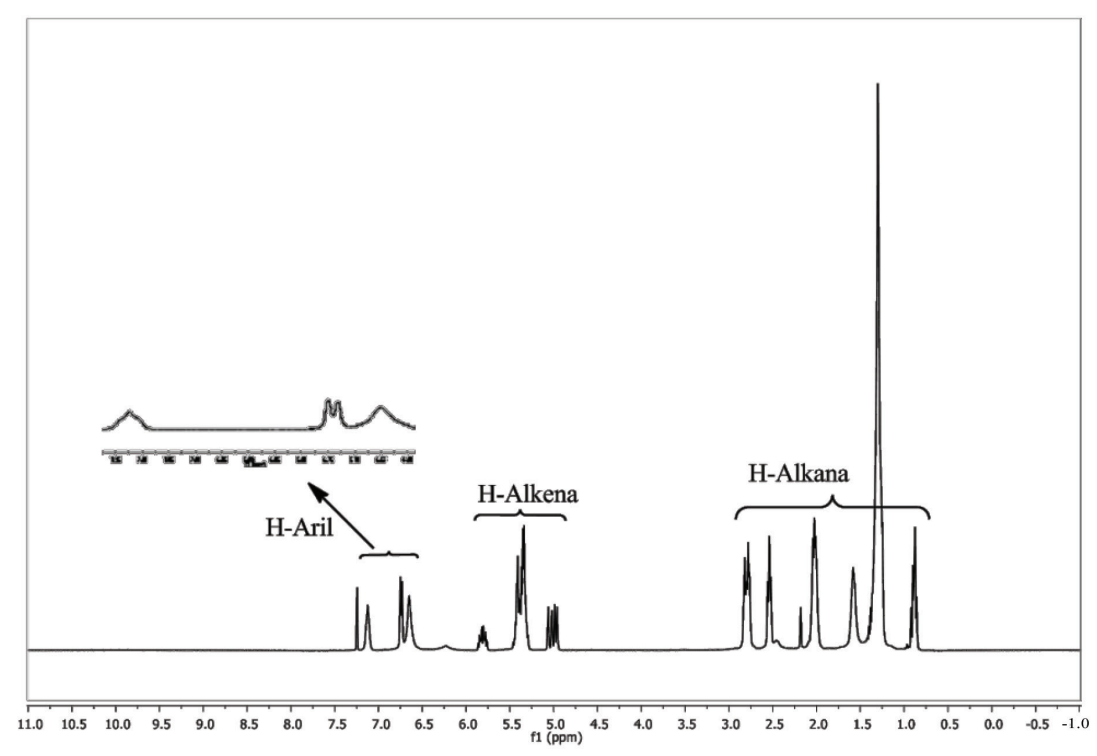

Figure 2: H NMR of isolated cardanol.

\subsection{H NMR Characterisation of Cardanol}

Obtained cardanol characterised using H NMR (Figure 2) showed the closest chemical shift with tetramethylsilane (TMS) at $\delta 0.857-0.919 \mathrm{ppm}$ $(\mathrm{m}, \mathrm{CH} 2 / \mathrm{CH} 3)$ which indicated as very end carbon of aliphatic chain.

Chemical shift around $\delta 1.248-2.832(\mathrm{~m}, \mathrm{CH} 2)$ ppm were belong to methylene groups of long aliphatic side chain. Besides these chemical shifts around $\delta 5.03-5.861(\mathrm{~m}, \mathrm{CH}) \mathrm{ppm}$ were estimated belong to alkenes protons whereas the presences of chemical shift in the area about $\delta 6.650-7.124(\mathrm{~m}, \mathrm{Ar}-\mathrm{H})$ ppm were indicated to existence of aryl proton. Because aryl protons are more electronegative than aliphatic protons made the position H NMR in the furthest position of the TMS.

\subsection{FTIR of CF Resin}

CF-based novolac resin was synthesised through polycondensation reaction with different purification methods. Comparison of FTIR spectra (Figure 4) of those purified resins showed similar typical functional groups of both $\mathrm{CF}$ resin, based on reaction mechanism shown in Figure 3. 


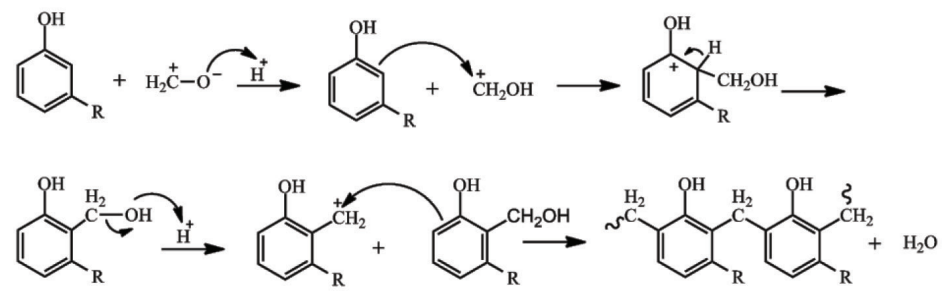

(a)

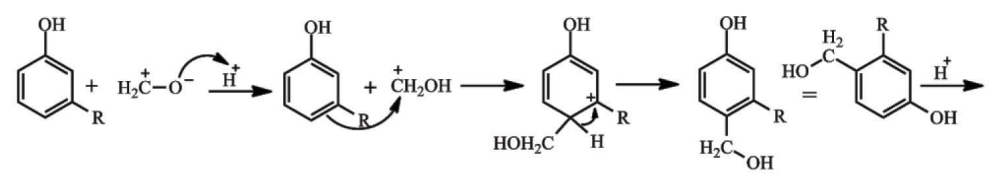

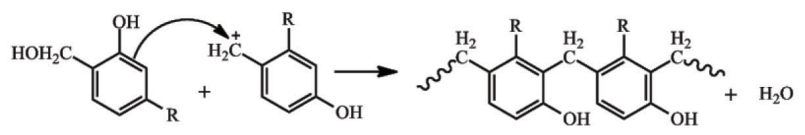

(b)

Figure 3: Polymerisation reaction of CF resin (a) ortho and (b) para substitution. . $^{13,14}$

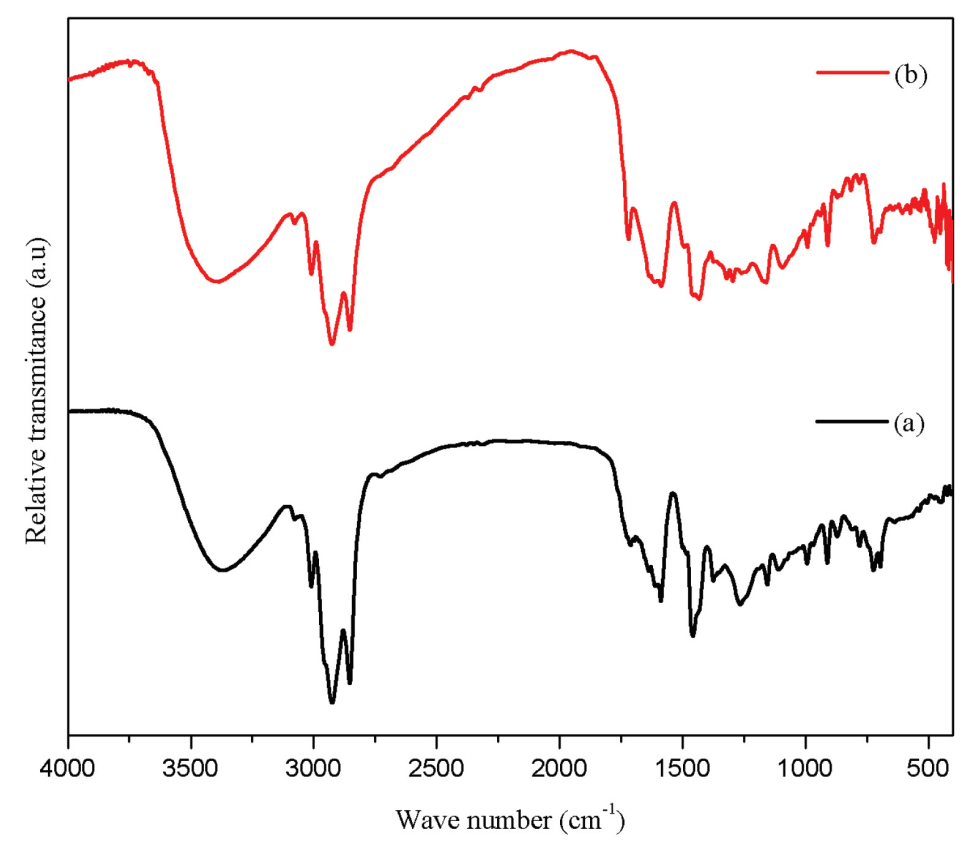

Figure 4. FTIR spectra of CF resin purified by (a) column chromatography and (b) methanol extraction. 
Aliphatic chain has not been affected by addition of formaldehyde. It was confirmed by the remaining adsorption around 3,077 and 3,010 $\mathrm{cm}^{-1}$ of $\mathrm{C}-\mathrm{H}$ alkenes. Besides, from the spectra comparison among cardanol (Figure 1) and both of resins, the presence of adsorption peak at $1,709 \mathrm{~cm}^{-1}$ and the occurrence of wave number shift from $1,074 \mathrm{~cm}^{-1}$ at cardanol became $1,111 \mathrm{~cm}^{-1}$ at resins showed methylation of cardanol due to substitution of $\mathrm{C}-\mathrm{O}$ group from $\mathrm{CH}_{2} \mathrm{OH}$ as explained by previous research. ${ }^{15}$ Adsorption intensity around $1,592(\mathrm{C}=\mathrm{C}$ stretching), 3,010 (C-H alkenes stretching) and $779 \mathrm{~cm}^{-1}$ (C-H deformation outof-plane) almost unaffected by addition of formaldehyde. Then, it was assumed that substitution $\mathrm{CH}_{2} \mathrm{OH}$ did not through double bond of side chain but aromatic group. ${ }^{16}$ FTIR analysis showed sharp adsorption at 870 and $779 \mathrm{~cm}^{-1}$ which was assumed as benzene nuclei substituted at para and ortho position, respectively.

\subsection{HNMR of CF Resin}

NMR spectra ofCF resin purified by column chromatography and methanol extraction method were shown in Figure 5. Chemical shift around 6.6-7.1 ppm indicated the presence of phenyl ring while chemical shifts around 4.9-5.7 ppm were methylene groups $(\mathrm{C}=\mathrm{CH} 2)$ from side chain double bonds. In addition, the chemical shift at $0.8-2.8 \mathrm{ppm}$ was from aliphatic carbon chain. A characteristics of CF resin was investigated from the presence of methylene bridge between of aromatic rings $\left(-\mathrm{CH}_{2}\right)$ around $3.6 \mathrm{ppm} .{ }^{16,17}$ It was related to the FTIR analysis data of those resin which showed that $\mathrm{CH}_{2} \mathrm{OH}$ substitution only through aromatic rings.

\subsection{Thermal Stability of CF Resin}

Thermal stability of CF resin was compared with synthesised commercial $\mathrm{CF}$ resin in the same condition. There were two degradation processes occurred in both of thermograms as shown in Figure 6 . The CF resin from isolated cardanol interpreted first degradation process at temperature range $210^{\circ} \mathrm{C}-282^{\circ} \mathrm{C}$ with $3.6 \%$ mass loss. It was occurred due to the loss of water, impurities and unreacted cardanol monomers. ${ }^{18,19}$ 


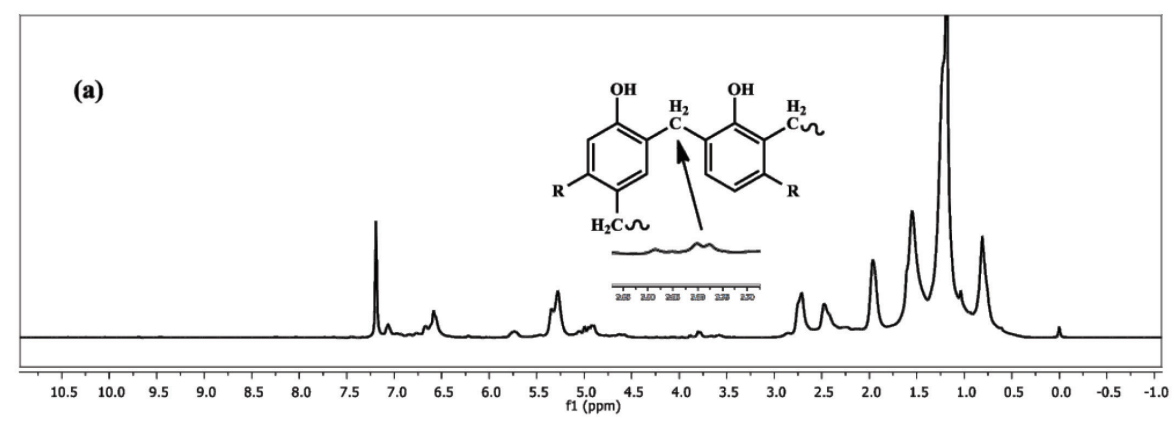

(b)

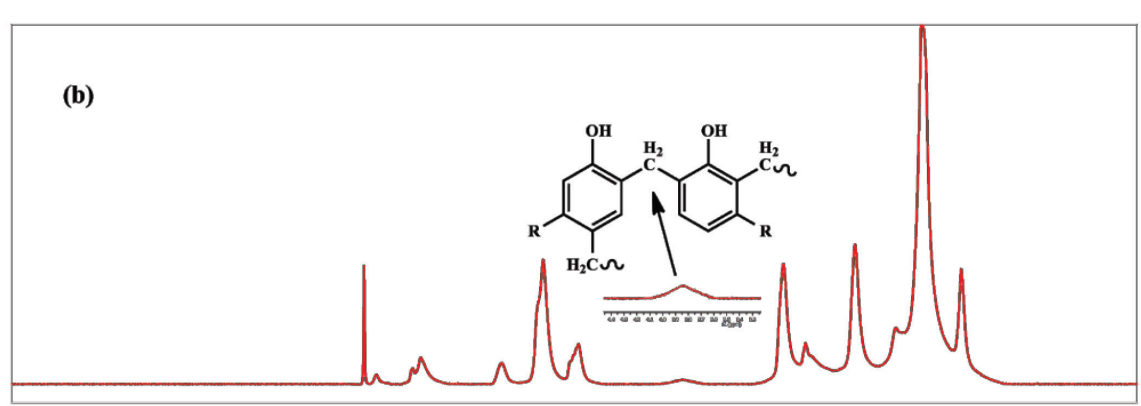

Figure 5: HNMR spectra of CF resin purified by (a) column chromatography and (b) methanol extraction.

The second degradation process at $282^{\circ} \mathrm{C}-557^{\circ} \mathrm{C}$, the $81.15 \%$ mass loss was occurred due to decomposition of resin which was supported by the emerged of two exothermic peak of DTA at temperature range $458^{\circ} \mathrm{C}-506^{\circ} \mathrm{C}$ as the depolymerisation and further decomposition of resin ${ }^{21,22}$ meanwhile commercial $\mathrm{CF}$ resin indicated the first mass loss $(48.75 \%)$ at temperature around $216.7^{\circ} \mathrm{C}-471.7^{\circ} \mathrm{C}$ caused the loss of water content, cardanol monomers and the break of aliphatic chain from aromatic ring of cardanol. Whereas, the second stage of degradation process consisted by decomposition was taken place at $471.7^{\circ} \mathrm{C}-600.5^{\circ} \mathrm{C}$ (with $24.95 \%$ mass loss). The presence of exothermic peak at $460^{\circ} \mathrm{C}-547^{\circ} \mathrm{C}$ espoused that occurrence. The TG-DTA analysis identified better thermal stability of synthesised CF resin from isolated cardanol than commercial cardanol. 

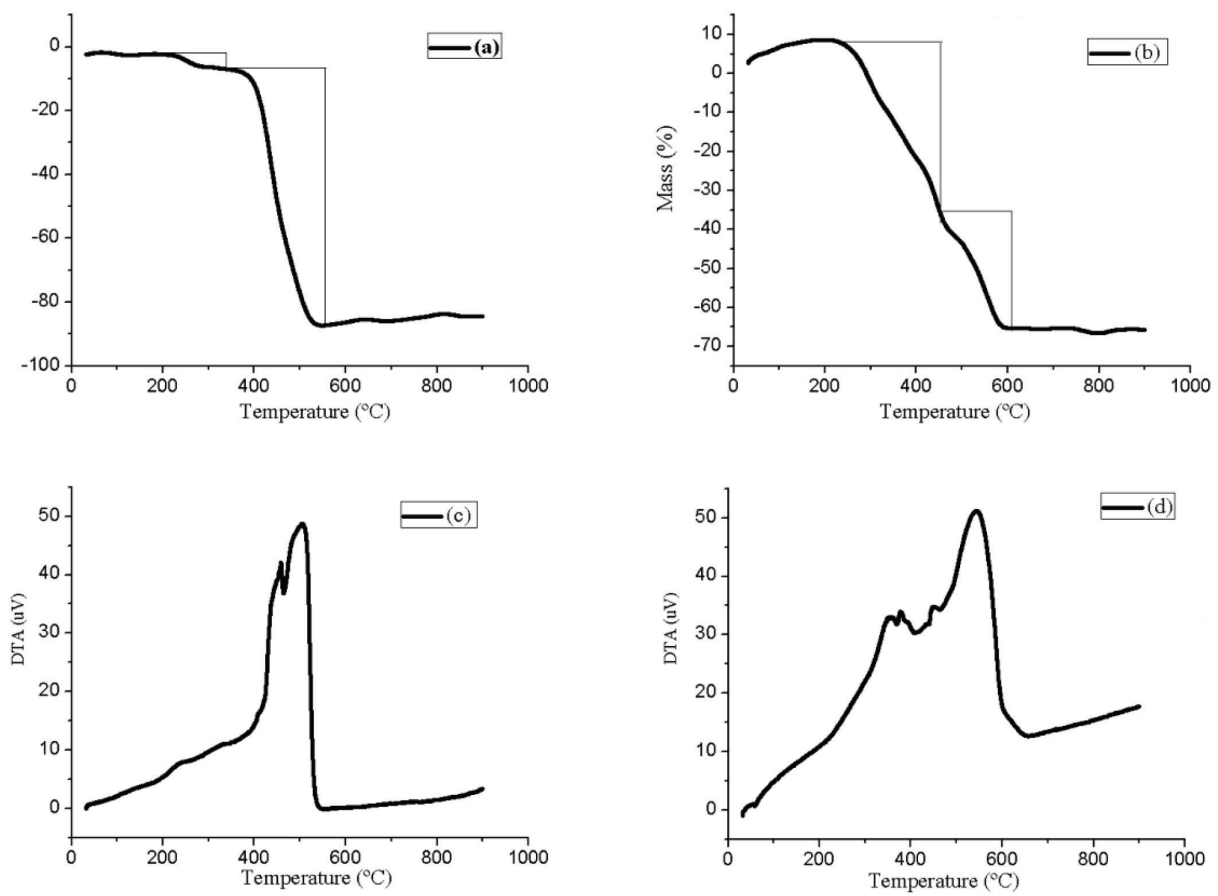

Figure 6: TG-DTA thermogram of ([a] and [c]) isolate-based CF resin and ([b] and [d]) commercial-based CF resin.

\section{CONCLUSION}

CF-based novolac resin was successfully synthesised through polycondensation reaction between cardanol and formaldehyde in acidic condition and already confirmed by FTIR spectrophotometry and 1H NMR spectroscopy whereas the thermal stability comparison of isolated and commercial CF resin was investigated by TG-DTA and showed higher degradation temperature of isolated cardanol-based CF resin.

\section{ACKNOWLEDGEMENTS}

Authors acknowledge to Sebelas Maret University for funding this research through Penelitian Unggulan Universitas Sebelas Maret Surakarta (UNS). 


\section{REFERENCES}

1. Balgude, D. \& Sabnis, A. S. (2014). CNSL: An environment friendly alternative for the modern coating industry. J. Coat. Technol. Res., 11(2), 169-183, https://doi.org/10.1007/s11998-013-9521-3.

2. Gurunath, P. V. \& Bijwe, J. (2007). Friction and wear studies on brakepad materials based on newly developed resin. Wear, 263(7), 1212-1219, https://doi.org/10.1016/j.wear.2006.12.050.

3. Rios, M. A. S. \& Mazzetto, S. E. (2009). Cashew nut shell liquid (CNSL) as source of eco-friendly antioxidants for lubricants. Proceedings of the 13th international electronic conference on synthetic organic chemistry. Basel, Switzerland: Molecular Diversity Preservation International.

4. Leite, A. S., Md., T. I., Antonio, L. G. J., Joao, M. C. S., Marcus, V. O. B. A., Marcia, F. C. J. P., Hercilia, M. L. R., Maria, G. F. M., Ana, A. C. M. -C. \& Jose, A. D. L. (2016). Pharmacological properties of cashew (Anacardium occidentale). Afr. J. Biotechnol., 15(35), 1855-1863, https:// doi.org/10.5897/ajb2015.15051.

5. Mdachi, S. J. M. (2013). The prevalence of natural 3-alk(en)yl-substituted phenols and their potential semisyntheses from cashew nut shell liquid. Tanzan. J. Sci., 39(1), 19-37.

6. Voirin, C., Caillol, S., Sadavarte, N. V., Tawade, B. V., Boutevin, B. \& Wadgaonkar, P. P. (2014). Polymer chemistry functionalization of cardanol: Towards biobased polymers and additives. Polym. Chem., 5(9), 3142-3162, https://doi.org/10.1039/c3py01194a.

7. Ikeda, R., Tanaka, H., Uyama, H. \& Kobayashi, S. (2002). Synthesis and curing behaviors of a crosslinkable polymer from cashew nut shell liquid. Polym., 43(12), 3475-3481, https://doi.org/10.1016/s00323861(02)00062-9.

8. Yadav, R. \& Srivastava, D. (2009). Studies on the process variables of the condensation reaction of cardanol and formaldehyde by response surface methodology. Eur. Polym. J., 45(3), 946-952, https://doi.org/10.1016/j. eurpolymj.2008.11.019.

9. Odian, G. (2004). Principles of polymerization. 4th Ed. Hoboken: John Wiley and Sons, Inc.

10. Weili, L. (2015). Analysis of synthesis of general purpose phenolic resin and its curing mechanism. APED, 10(2), 135-139.

11. Raquez, J., Deléglise, M., Lacrampe, M. \& Krawczak, P. (2010). Thermosetting (bio) materials derived from renewable resources: A critical review. Prog. Polym. Sci., 35(4), 487-509, https://doi.org/10.1016/j. progpolymsci.2010.01.001. 
12. Kumar, P. P., Paramashivappa, R., Vithayathil, P. J., Rao, P. V. S. \& Rao, A. S. (2002). Process for isolation of cardanol from technical cashew (Anacardium occidentale L.) nut shell liquid. J. Agric. Food Chem., 50(16), 4705-4708, https://doi.org/10.1021/jf020224w.

13. Liu, Z., Huo, J. \& Yu, Y. (2017). Water absorption behavior and thermalmechanical properties of epoxy resins cured with cardanol-based novolac resins and their esterified ramifications. Mater. Today Commun., 10, 8094, https://doi.org/10.1016/j.mtcomm.2017.01.007.

14. Natarajan, M. \& Murugavel, S. C. (2013). Synthesis, spectral and thermal degradation kinetics of novolac resins derived from cardanol. High Perform. Polym., 25(6), 685-696, https://doi.org/10.1177/0954008313482955.

15. McMurry, J. (2011). Fundamental of organic chemistry. 7th Ed. Belmont, CA: Brooks/Cole Cengage Learning.

16. Devi, A. \& Srivastava, D. (2007). Studies on the blends of cardanolbased epoxidized novolac type phenolic resin and carboxyl-terminated polybutadiene (CTPB), I. Mat. Sci. Eng. A, 458(1), 336-347, https://doi. org/10.1016/j.msea.2006.12.081.

17. Tiwari, D., Devi, A. \& Chandra, R. (2011). Synthesis of cardanol based phenolic resin with aid of microwaves. Int. J. Drug Dev. Res., 3(2), 171175.

18. Sultania, M., Rai, J. S. P. \& Srivastava, D. (2010). Studies on the synthesis and curing of epoxidized novolac vinyl ester resin from renewable resource material. Eur. Polym. J., 46(10), 2019-2032, https://doi.org/10.1016/j. eurpolymj.2010.07.014.

19. Mythili, C. V, Retna, A. M. \& Gopalakrishnan, S. (2004). Synthesis, mechanical, thermal and chemical properties of polyurethanes based on cardanol. Bull. Mater. Sci., 27(3), 235-241, https://doi.org/10.1007/ bf02708512.

20. Papadopoulou, E. \& Chrissafis, K. (2011). Thermal study of phenolformaldehyde resin modified with cashew nut shell liquid. Thermochim. Acta, 512(1), 105-109, https://doi.org/10.1016/j.tca.2010.09.008.

21. Gopalakrishnan, S. \& Fernando, T. L. (2010). Processability and characteristics of novel polyurethanes from cardanol. Res. J. Pharm. Biol. Chem. Sci., 1(4), 252-261.

22. Loureiro, T., Macarena, R., Dip, M., Lucas, E. \& Spinelli, L. (2017). Cardanol polymerization under acid conditions by addition and condensation reactions. J. Polym. Environ., 26(2), 555-566, https://doi. org/10.1007/s10924-017-0969-6. 